\section{A SAÚDE MENTAL DE ESTUDANTES UNIVERSITÁRIOS: BREVE PANORAMA E ALGUMAS INICIATIVAS DE PROMOÇÃO}

\section{THE MENTAL HEALTH OF UNIVERSITY STUDENTS: A BRIEF OVERVIEW AND SOME PROMOTION INITIATIVES}

Edleusa Nery Garrido ${ }^{1, *} /$ Alessandra Barbosa dos Santos ${ }^{1}$ / Gabriel de Jesus Santos ${ }^{1} /$ Geovana Amorim dos Santos ${ }^{1}$ / Gustavo de Barros Araújo Muniz ${ }^{1 /}$ Mariana Souza Guimarães ${ }^{1}$ / Núbia Menezes Teixeira ${ }^{1}$ / Vinícius Coelho do Nascimento

\section{INTRODUÇÃO}

Como já é amplamente difundida, a concepção de saúde necessita ser vista na perspectiva de um modelo que integre fatores biológicos, psíquicos, sociais, culturais, de classe, espirituais e ambientais, dentre outros. Essa concepção é respaldada pela clássica definição do que é compreendido como saúde segundo a Organização Mundial da Saúde (OMS), publicada no ano de 2002. No que tange à saúde mental, esta é vista a partir de uma relação sócio-histórica, definida pela cultura e legitimada pelo senso comum. Dentro das relações que o sujeito mantém com seu grupo social, uma teia de significados sobre a relação entre saúde e doença é construída, o que aponta o caráter social e cultural desse conceito (PEREIRA; VIANA, 2009).

A concepção de saúde mental é, portanto, multifatorial e vem sendo modificada ao longo do tempo, resultando como um desafio conceituá-la completamente. Em um relatório da OMS, a saúde mental é trazida como a abrangência de "um estado de bem-estar no qual um indivíduo percebe suas próprias habilidades, pode lidar com os estresses cotidianos, pode trabalhar produtivamente e é capaz de contribuir para sua comunidade" (OMS, 2002 apud GAINO et al., 2018, p. 110).

Apesar dos esforços, a definição de bem-estar, atrelada à saúde e à saúde mental continua sendo controversa na literatura, principalmente devido ao seu caráter subjetivo e particular (GALDERISI et al., 2015). O próprio conceito também sofre variações conforme a cultura que o define.

\begin{abstract}
RESUMO
O ambiente acadêmico apresenta desafios que podem trazer implicações na saúde mental de estudantes de Instituições do Ensino Superior (IES). OBJETIVOS: revisar estudos que evidenciam a saúde mental de estudantes brasileiros e elencar serviços oferecidos pelas IES, voltados à minimização dos impactos da vida acadêmica no adoecimento psíquico destes. MÉTODO: Identificou-se 23 artigos sobre aspectos da saúde mental e cinco relativos a serviços de atenção ao estudante, a partir da análise temática. RESULTADOS: constatou-se três grupos: saúde mental de forma ampla (saúde mental, qualidade de vida, sofrimento psíquico); aspectos específicos (estresse, depressão, síndrome de Burnout, Bullying, consumo de substâncias psicoativas e suicídio); morbidades relacionadas (anorexia nervosa e distúrbios da imagem). Predominam, nas instituições, ações a partir da demanda espontânea. CONCLUSÃO: há necessidade de políticas no âmbito das IES, redutoras do sofrimento psíquico e promotoras da saúde mental.
\end{abstract}

Palavras-chave: Estudante universitário. Saúde mental Revisão de literatura.

\section{ABSTRACT}

The academic environment presents challenges that may have implications for the mental health of students from higher education institutions (HEI). OBJECTIVES: to review studies that demonstrate the mental health data of Brazilian students and to list services offered by the HEIs in order to minimize the impacts of academic life on their psychological condition. METHOD: based on a thematic analysis, 23 articles about aspects of mental health and five related to student care services were identified. RESULTS: three groups were found: broad mental health (mental health, quality of life, psychological distress); specific aspects (stress, depression, Burnout syndrome, bullying, consumption of psychoactive substances and suicide); related morbidities (anorexia and image disorders). In institutions, mental health services based on spontaneous demand predominate. CONCLUSION: The HEI ought to formulate policies which reduce psychological distress and promote mental health.

Keywords: University student. Mental health. Literature review.

Submetido em: 20 de jul. 2020

Aceito em: 11 de dez. 2020

${ }^{1}$ Universidade do Estado da Bahia - UNEB, Salvador, Bahia - Brasil

*E-mail para correspondência: edleusagarrido@gmail.com

Rev. ComCiência - dez. 2020, vol. 5, no. 7, p. 77-85 / doi: 10.36112/issn2595-1890.v5.i7.p77-85 
É proposta pelos autores uma concepção de saúde mental mais fluida, com ênfase em um estado dinâmico de equilíbrio interno, concebendo o indivíduo como capaz de reconhecer, expressar e modular suas próprias emoções, assim como empatizar com outros, apresentando, assim, uma relação harmônica entre corpo e mente. Aquele estudo também destaca a importância da flexibilidade e habilidade para lidar com adversidades e a compreensão das funções nos diferentes papéis sociais.

Dentro da esfera ampla da saúde mental é fundamental abordar também a concepção de sofrimento psíquico que, embora seja comumente trazido na literatura recente, a exemplo das publicações de Oliveira et al. (2018) e Perrusi (2015), há mais estudos que utilizam essa concepção do que a definem. Nessa direção, é preciso destacar que a OMS (2012) traz uma série de determinantes que contribuem para a saúde mental e a limitação destes pode estar associada com o sofrimento psíquico e o adoecimento do indivíduo. No documento, são relatados: atributos individuais e comportamentais, que abrangem características genéticas, emocionais, cognitivas, capacidade para lidar com adversidades e contextos sociais, entre outras; nos determinantes sociais e econômicos estão fatores como oportunidades de trabalho, educação, renda, transporte, segurança, capacidade de se engajar positivamente com membros da família, amigos ou colegas e por último, são trazidos determinantes ambientais, tais como acesso a água, saneamento básico, discriminação racial, de gênero, exposição a desastres e conflitos armados.

Santana e Gondin (2016), em seu estudo sobre auto regulação emocional, trazem como um dos principais conceitos o bem-estar o qual, embasados por vários autores, definem o constructo a partir de duas vertentes: a hedônica e a eudaimônica. A primeira consiste em um bem-estar subjetivo que se caracteriza pela forma com que o sujeito avalia o seu nível de satisfação com a vida, incluindo também a frequência que experimenta emoções positivas e negativas. A segunda corrente apresenta o bem-estar psicológico, este marcado pelo desenvolvimento humano, propósito de vida e desenvolvimento obtido a partir da superação de dificuldades.

Quando nos reportamos à vida estudantil no Ensino Superior, é importante considerarmos todos esses determinantes citados anteriormente como impactantes ao bem-estar subjetivo e psicológico, especialmente quando levamos em conta a pluralidade da população discente desse segmento ao longo dos últimos anos, advindos de políticas de inclusão (COSTA; GOULART, 2018). Isto posto, o presente artigo tem como objetivos levantar estudos que colocam em evidência aspectos da saúde mental de estudantes brasileiros(as) bem como ilustrar algumas iniciativas de serviços oferecidos pelas Instituições de Ensino Superior (IES) que tenham o propósito de minimizar os impactos da vida acadêmica no adoecimento psíquico e promover a saúde mental desse segmento.

\section{ASPECTOS METODOLÓGICOS}

Sem a pretensão de esgotar a literatura sobre o assunto e com o intuito de trazer uma breve fotografia do panorama existente, escolhemos o recorte temporal de produções do ano de 2018. Fizemos um levantamento nas plataformas do Scielo, Bireme e Redalyc, utilizando-nos dos descrito- res: saúde, saúde mental e sofrimento psíquico, correlacionando-os com estudante universitário(a), estudante do Ensino Superior e graduando(a). Levantamos 102 artigos e, descartados aqueles que tratavam de outras nuances da saúde, identificamos 23 relativos à aspectos da saúde mental, a partir da leitura dos resumos. Para a identificação de iniciativas institucionais voltadas para a saúde mental dos estudantes, o recorte foi a partir de 2018. Localizamos 16 artigos, sendo que apenas cinco, atendiam ao critério de narrar as iniciativas oferecidas na IES. Para categorização, a partir da Análise de Conteúdo prescrita por Bardin (2009), consideramos apenas os estudos que apresentassem a relação entre saúde mental e vida estudantil. Chegamos a duas categorias de análise: sofrimento psíquico e iniciativas institucionais minimizadoras e preventivas do sofrimento psíquico e/ou promotoras da saúde mental. Em adição, sistematizamos algumas das características dos estudos selecionados.

\section{RESULTADOS E DISCUSSÃO}

Constatamos que, dos 23 resumos dos artigos encontrados, 17 são destinados a aspectos relativos à saúde mental de estudantes dos diversos cursos de saúde, em especial, de Medicina e Enfermagem. Além disso, há predominância do sexo feminino nas amostras e a faixa etária concentrada na juventude. As questões étnico raciais em geral, bem como as condições socioeconômicas, por sua vez, foram exploradas de forma superficial e esporádicas nesses estudos.

Houve predominância de pesquisas de natureza quantitativa, sendo 20 artigos representativos dessa categoria, dois foram descritos como qualitativos e apenas um na modalidade 
mista. Para este resultado, é importante enfatizar que a pesquisa quantitativa é de grande contribuição para estudos populacionais, especialmente porque trazem um panorama geral de fenômenos que se apresentam naquelas amostras, pois, como afirma Jones (2015, p. 275), "grande parte do trabalho quantitativo é 'mapeamento social' e esta contagem e estimativa de prevalência e mudança também é importante para saber o que se passa no mundo." Sendo assim, os resultados das pesquisas levantadas, trazem evidências do que se passa no mundo estudantil, considerando o período em que os dados foram produzidos. No entanto, tendo em vista a preponderância de estudos que trazem como sujeitos estudantes da área de saúde, compreendemos como lacuna significativa, pesquisas que abarquem estudantes das demais áreas de formação.

Também queremos destacar que, embora o presente texto não se configure como um estudo exaustivo, é possível inferir, pelo panorama encontrado, carência de pesquisas de natureza qualitativa. Reiteramos sua importância, uma vez que é o tipo de pesquisa que "permite compreender e classificar processos dinâmicos vividos por grupos sociais, contribuir no processo de mudança de determinado grupo e possibilitar, em maior nível de profundidade, o entendimento das particularidades do comportamento dos indivíduos" (RICHARDSON, 2011, p. 80).

Quanto aos instrumentos mais comumente empregados, constatamos que houve predominância de escalas, inventários e questionários. O Inventário de Depressão de Beck (BDI) foi observado como o de aplicação mais frequente nas investigações, seguido do Inventário de Sintomas de Stress para Adultos de Lipp (ISSL), e a Avaliação de Qualidade de Vida, versão abreviada (WHOQOL-Bref), assim como o Questionário de Vivências Acadêmicas-reduzido (QVA-r). Como instrumentos bastante utilizados para aplicação em estudantes universitários, constatamos o uso de questionários sociodemográficos, aplicados por grande parte dos autores e autoras dos 23 artigos analisados.

Observamos também a presença de vários instrumentos específicos para a avaliação de estresse em estudantes universitárias, sendo estes o ISSL, a Escala de Estresse Percebido (PSS), a Escala de Estressor Vocacional (EEV), o Inventário de Ansiedade de Becker (BAI) e a Escala de Estresse Acadêmico (EEA). Além disso, são adotados os instrumentos mistos que medem ansiedade e depressão como é o caso da Escala Hospitalar de Ansiedade e Depressão (HADS).

Um importante dado a ser ressaltado é a predominância de estudos com temáticas mais amplas, em comparação com estudos mais específicos. Diversos trabalhos abordam temas como qualidade de vida e saúde mental, propondo uma visão mais macro sobre a saúde mental de estudantes universitários. Também há aqueles que, embora discutam aspectos macro, estão voltados para questões específicas como estresse, ansiedade, Síndrome de Burnout e depressão, dentre outros.

A categoria sofrimento psíquico está sistematizada no Quadro 1 acima, composta por três subcategorias temáticas a saber: aspectos macro sobre a saúde mental; aspectos específicos sobre saúde mental e outras morbidades que se relacionam com a saúde mental. Nota-se que embora alguns autores se ocupem em trazer a saúde mental dos estudantes de forma mais ampla, como qualidade de vida e sofrimento psíquico, são os aspectos específicos que predominam: estresse, depressão, Síndrome de Burnout, bullying, ansiedade e comportamentos que afetam a saúde mental como o consumo de substâncias psicoativas, incluindo os medicamentos antidepressivos. Além disso, aparece um artigo em que a temática do suicídio é retratada e duas publicações cujo foco e o sofrimento decorrente de dificuldades com a autoimagem.

QUADRO 1 - TEMAS PRESENTES NOS ARTIGOS SOBRE A SAÚDE MENTAL DA POPULAÇÃO DISCENTE DO ENSINO SUPERIOR

\begin{tabular}{|c|c|c|}
\hline $\begin{array}{l}\text { Aspectos } \\
\text { macro } \\
\text { sobre a } \\
\text { saúde } \\
\text { mental }\end{array}$ & $\begin{array}{l}\text { Aspectos específicos sobre } \\
\text { saúde mental }\end{array}$ & $\begin{array}{c}\text { Outras } \\
\text { morbidades } \\
\text { que se } \\
\text { relacionam } \\
\text { com a saúde } \\
\text { mental }\end{array}$ \\
\hline $\begin{array}{l}\text { Qualidade } \\
\text { de vida: } \\
\text { Amorim et } \\
\text { al., (2018); } \\
\text { Freitas et } \\
\text { al., (2018); } \\
\text { Ribeiro et } \\
\text { al., (2018); } \\
\text { Santos, } \\
\text { Almeida e } \\
\text { Anacleto } \\
\text { (2018) }\end{array}$ & $\begin{array}{l}\text { Estresse: Amorim et al., } \\
\text { (2018); Costa } \text { et al., (2018); } \\
\text { Duarte } \text { et al., (2018); Freitas } \text { et } \\
\text { al., (2018); Irsch } \text { et al., (2018); } \\
\text { Ribeiro et al., (2018); Santos, } \\
\text { Almeida e Anacleto (2018) }\end{array}$ & $\begin{array}{l}\text { Anorexia } \\
\text { nervosa: } \\
\text { Araújo } \\
\text { Custódio } \\
\text { (2018) }\end{array}$ \\
\hline $\begin{array}{l}\text { Saúde } \\
\text { mental: } \\
\text { Amorim et } \\
\text { al., (2018); } \\
\text { Carleto et } \\
\text { al., (2018) } \\
\text { e Gil et al., } \\
\text { (2018); } \\
\text { Irsch et al., } \\
\text { (2018) }\end{array}$ & $\begin{array}{l}\text { Depressão: Araújo (2018); } \\
\text { Fernandes et al., (2018); Leão } \\
\text { et al., (2018); Ribeiro et al., } \\
\text { (2018); Toti, Bastos e Rodri- } \\
\text { gues (2018) }\end{array}$ & $\begin{array}{l}\text { Distúrbios de } \\
\text { imagem: } \\
\text { Silva et al., } \\
\text { (2018) }\end{array}$ \\
\hline $\begin{array}{l}\text { Sofrimento } \\
\text { psíquico: } \\
\text { Murakami } \\
\text { et al., } \\
\text { (2018); } \\
\text { Riondina et } \\
\text { al., (2018); } \\
\text { Silva e } \\
\text { Daltro } \\
(2018)\end{array}$ & $\begin{array}{l}\text { Bullying: Borges, Lopes e } \\
\text { Lopes (2018); } \\
\text { Ansiedade: Fernandes et al., } \\
\text { (2018) } \\
\text { Consumo de substâncias } \\
\text { psicoativas/antidepressivos: } \\
\begin{array}{l}\text { Pereira e Miceli (2018); } \\
\text { Rondina et al., (2018) } \\
\text { Suicídio: Silva e Azevedo } \\
\text { (2018) }\end{array}\end{array}$ & \\
\hline
\end{tabular}

Fonte: sistematização produzida pelos autores.

Chama atenção a predominância de produções relativas ao estresse e à depressão dos estudantes, as quais destacaremos aqui. Estresse é compreendido como uma resposta física e psicológica às situações (estas entendidas como eventos estressores) que 
promovam estados de confusão, provoquem medo, irritação, excitação ou emoção profunda, levando o sujeito à felicidade ou a tristeza, conforme Lipp (1996 apud MACHADO; VEIGA; ALVES, 2011). A dinâmica acelerada que vivemos, impõe um conjunto de exigências em que somos impelidos a dar conta diariamente e no cotidiano estudantil isso se apresenta, entre outros aspectos, a partir do volume de leituras, tarefas e avaliações. São, portanto, elementos estressores que, se não bem dosados e administrados, podem levar à exaustão e/ou à depressão.

Sobre depressão, como se vê no Quadro 1, são elencados cinco estudos que tratam do tema. De acordo com a OMS, os transtornos depressivos são caracterizados por tristeza, desinteresse, ausência de prazer, bem como é comum sentimento de culpa, comprometimento da autoestima e ainda podem levar a perda de apetite, dificuldades para dormir, cansaço, assim como dificuldades de concentração (PAHO, 2017). Tendo em vista as pressões que a vida acadêmica impõe e o estilo de vida que comumente os estudantes levam, como por exemplo, poucas horas de sono e muitas vezes alimentação irregular, aliado a outros prováveis fatores de risco préexistentes $^{2}$, esse grupo encontra-se em vulnerabilidade para o desenvolvimento de transtornos depressivos, apontando para o imperativo de conhecermos, de forma mais profunda, o perfil dos estudantes do Ensino Superior brasileiro e a forma com que o cotidiano estudantil afeta esses sujeitos.

${ }^{2}$ Outros fatores de risco para a depressão são: pobreza, desemprego, perda de pessoas queridas, rupturas sentimentais, enfermidades físicas $\mathrm{e}$ prejuízos causados pelo abuso de álcool e outras substâncias psicoativas (PAHO, 2017).
Nesse sentido, destacamos a iniciativa da Associação Nacional dos Dirigentes das Instituições Federais de Ensino Superior (ANDIFES), que vem, desde a década de 1990, apresentando pesquisas sobre o perfil socioeconômico e cultural dos graduandos das Instituições Federais de Ensino Superior (IFES). Essas produções colaboraram para a criação de uma Política de Assistência Estudantil no País, a partir do Decreto n 7.234 de 19/06/2010 (FONAPRACE, 2019).

No que tange à saúde dos estudantes, observamos que no IV Relatório, publicado em 2014, houve a inclusão de tópicos relacionados à qualidade de vida: "alimentação, prática de atividades físicas, utilização dos serviços de saúde e consumo de substâncias psicoativas" (FONAPRACE, 2016, p. 194). Notamos que o foco se concentra no perfil das práticas desempenhadas pelos estudantes bem como seus comportamentos.

Observamos que há um avanço no detalhamento sobre a vida estudantil, com ampliação da análise de vários aspectos daquela população, no documento disponível em 2019 e relativo aos dados produzidos em 2018 (FONAPRACE, 2019). Na edição, são trazidos os resultados decorrentes do processo que contou com cerca de 420 mil estudantes diretamente, cujo levantamento de dados incluiu, além do perfil básico (gênero, raça e idade), o percurso estudantil pregresso e outras informações relevantes, tais como: fontes de informação; domínio do computador; domínio de línguas estrangeiras; incremento cultural; dificuldades para estudar; relacionamentos; violências; intolerâncias; vulnerabilidades sociais; problemas pedagógicos; saúde física e mental; assédio moral; evasão e trancamentos e; pers- pectivas de futuro. No tópico sobre saúde mental, a pesquisa revelou que

[...] um percentual bem maior de estudantes que os associam com as dificuldades para estudar. Eles atingiram $23,7 \%$ do público pesquisado e os perfis apresentam polarizações mais nítidas e perceptíveis. Parte-se das pessoas do sexo feminino para se constatar que são vítimas muito mais recorrentes $(28,6 \%)$ do que as de sexo masculino $(17,7 \%)$. Racialmente, os problemas emocionais são mais numerosos para pessoas brancas $(26,2 \%)$, indígenas aldeadas $(25,1 \%)$ e pretas não quilombolas $(24,7 \%)$ [...] (FONAPRACE, 2019, p. 172).

A V Pesquisa da Andifes evidencia os diversos aspectos da vida estudantil que afetam os estudantes. $\mathrm{O}$ aprofundamento desses resultados pode ser implementado a partir de estudos com a aplicação de instrumentos sensíveis às questões de natureza subjetiva, notadamente aqueles de cunho qualitativo. Em nosso breve levantamento, conforme já foi dito, a concentração das pesquisas, em sua grande maioria, era de natureza quantitativa, havendo uma limitação nas investigações de aspectos mais subjetivos e individuais. Portanto, considerando a dimensão do sofrimento psíquico, estudos qualitativos que busquem compreender questões que abarquem a subjetividade dos sujeitos, neste caso, referente à dinâmica do estudante universitário, podem cooperar para entendimento das vivências que causam sofrimento, assim como levantar as reais necessidades do segmento estudantil.

Além de estudos que investigaram aspectos da saúde mental da população estudantil do Ensino Superior, sistematizamos iniciativas existentes em algumas IES brasileiras, o que veio 
a compor a segunda categoria temática: iniciativas institucionais minimizadoras e preventivas do sofrimento psíquico e/ou promotoras da saúde mental. São instituições que prestam serviços voltados para o acolhimento, a escuta e outra ações preventivas do sofrimento psíquico e promotoras da saúde mental. Verificamos que quatro regiões do País estão representadas nas experiências aqui reunidas.

Em funcionamento desde o ano de 1990, o Centro de Apoio Educacional e Psicológico (CAEP) é uma iniciativa de uma IES pública brasileira cujo objetivo é o de planejar e colocar em prática programas voltados para apoio e prevenção de dificuldades emocionais e acadêmicas, no período de formação de graduandos de diversos cursos da área de saúde (MURAKAMI et al., 2018). Citam os autores que, dentre as diversas ações do CAEP voltadas para a população discente, estão a assistência psicológica e educacional, o programa de tutoria, as oficinas de orientações psicopedagógicas/pedagógicas e os grupos de reflexão.

Também destinado aos estudantes da área de saúde, o Grupo de Apoio Psicopedagógico aos Estudantes de Medicina e Enfermagem (GRAPEME) é uma iniciativa da Faculdade de Ciências Médicas da Universidade Estadual de Campinas (Unicamp). Atualmente o GRAPEME oferece psicoterapia breve aos discentes, além de conteúdos de orientação e prevenção no interior de diversas disciplinas (TAMASHIRO et al., 2019). Conforme as autoras, nos últimos anos o GRAPEME vem desenvolvendo junto às turmas de primeiro ano, intervenções em grupo, com vistas a diminuir o impacto das dificuldades de adaptação dos discentes: formas de estudar, gestão de tempo, necessidade de lazer, dentre outros aspectos relativos ao cotidiano acadêmico.

Outra experiência de oferta de psicoterapia breve voltada aos discentes é trazida por Neves et al., (2019), ao relatarem um projeto extensionista, o qual instituiu o Espaço de Atenção Psicossocial (EPSICO) em uma universidade pública no Amazonas. Entre as principais queixas mencionadas pelos estudantes foram encontradas:

[...] ideação e/ou tentativas de suicídio; ansiedade; problemas afetivos de relacionamento; abuso sexual; assédio moral e sexual dentro da universidade; necessidade de maior organização do tempo de estudos; orientação profissional; conflitos decorrentes da insatisfação com o curso e da incerteza de manter a opção escolhida; dificuldades de planejamento de vida, relacionamento interpessoal docente-discente, incluindo aspectos das expectativas profissionais e pessoais (NEVES et al., 2019, p. 536)

Observamos que, a despeito de algumas das queixas trazidas neste estudo extrapolarem o âmbito acadêmico, há o predomínio daquelas relativas à dinâmica da vida estudantil. Tais resultados realçam a importância de refletirmos sobre o quanto esse espaço pode ser favorável ao adoecimento, assim como da necessidade de iniciativas que acolham o sofrimento discente.

\section{Preconizada pela OMS} (2002), as Práticas Integrativas e Complementares (PICS) contribuem na compreensão de integralidade da atenção à saúde. No Brasil, atua como coadjuvante na política de Humanização do Sistema Único de Saúde (SUS) (BRASIL, 2015). Neste sentido, a partir da iniciativa de profissionais do laboratório de PICS, a Universidade Federal do Sul da Bahia (UFSB) vem assistindo aos estudantes, de forma complementar a outros serviços oferecidos pela instituição, tendo realizado em 2018, em torno de 213 atendimentos individuais de acupuntura e auriculoterapia em estudantes com queixas de "ansiedade, labilidade emocional, dores cervicais e lombares, insônia, estados de desânimo, além de cefaleia e falta de concentração, muitas delas concomitantes" (BELASCO; PASSINHO; VIEIRA, 2019, p. 109). De acordo com essas autoras, boa parte dos estudantes que foram atendidos, apontaram, em sessões subsequentes, diminuição dos sintomas assim como melhor adaptação à dinâmica acadêmica que, na maior parte das vezes, é favorecedora desses sofrimentos.

Com iniciativas voltadas para a prevenção, o Projeto de extensão denominado Pega Leve - saúde mental do estudante universitário, desenvolvido pela Universidade Federal do Rio Grande do Sul (UFRGS), treina gatekeepers $^{3}$, esses graduandos atuam "como ferramenta de promoção e prevenção em saúde mental nessa população, permitindo a criação de redes de apoio, identificação precoce dos casos de risco e encaminhamento adequado para serviço de saúde mental" (ARENAS et al., 2019, p. 519).

Apesar dos esforços por parte de diversas IES, nem sempre as ações voltadas para a saúde dos estudantes são perenes, como é o caso daquelas ocorridas na Universidade Federal do Espírito Santo (UFES), como registram Ramos et al. (2018). No texto são descritas as intervenções psicológicas voltadas para a população discente no período de 2015 a 2017, totalizando 705 estudantes atendidos. As ações foram: "1. Acolhimento e triagem psicológica; 2. oficinas: de preparação

${ }^{3}$ Guardiões, promotores da saúde [tradução nossa]. 
para a vida acadêmica, de habilidades sociais, de controle da ansiedade e enfrentamento do estresse, de orientação aos estudos, e de temática específica; 3. psicoterapia individual; e 4. educação para a carreira" (Idem, p. 221), resultante da convergência de três projetos de extensão articulados com instâncias da assistência estudantil institucional.

Conforme preconizam os autores, essa articulação deve ocorrer no que tange ao fomento (espaço físico, materiais, recursos financeiros para os projetos bolsas), assim como a conscientização da comunidade acadêmica sobre a importância das ações. Salientam ainda que as diversas instâncias de gestão institucional "possuem competência para o alinhamento de estratégias e recursos que viabilizem não só o sucesso das ações psicossociais dirigidas aos graduandos, mas também a manutenção do compromisso ético das instituições públicas de Ensino Superior com o futuro do país" (RAMOS et al., 2018, p. 230).

Neste sucinto levantamento do panorama de iniciativas, observamos que há esforços institucionais no sentido de acolher o sofrimento psíquico da população estudantil, apesar da predominância dos atendimentos da demanda espontânea e com alcance limitado. Há também ações que visam promover o bem-estar e a saúde dos estudantes, ainda que a partir de ações pontuais, como aquelas oferecidas em atividades extensionistas. Para que medidas curativas e preventivas possam ser implementadas, compreendemos como indispensáveis pesquisas abrangentes e aprofundadas sobre a saúde dos estudantes como forma de subsidiar essas medidas, além de gestão institucional e garantia de infraestrutura adequada à implantação das ações.

\section{CONSIDERAÇÕES FINAIS}

Embora importante e necessárias, as pesquisas identificadas no presente estudo retratam realidades específicas e se referem às IES públicas. Tendo em vista que a população do Ensino Superior se concentra nas IES privadas, com 87,9\%, (INEP, 2019), pouco sabemos sobre esse público e sobre medidas promotoras da saúde deste. Outro aspecto que chama atenção é a necessidade de conhecermos quem são os estudantes que aparecem nos estudos, para identificação dos grupos mais vulneráveis e, assim, desenvolver ações voltadas para necessidades específicas de enfrentamento ao sofrimento psíquico. Diante da expansão do Ensino Superior nas últimas décadas, não é mais possível conceber a população estudantil desse segmento no Brasil como um todo homogêneo, havemos de levar em conta toda a diversidade existente e, consequentemente, suas demandas específicas.

Compreendemos que nem todo sofrimento psíquico é decorrente do ambiente acadêmico, mas entender como este impacta na saúde mental dos estudantes, é estarmos empenhados em refletir e construir uma dinâmica nesses espaços que possa minimizar os fatores estressantes existentes. É, pois, um convite a repensarmos as IES brasileiras como lócus promotores do desenvolvimento humano de forma salutar.

\section{REFERÊNCIAS}

AMORIM, Bruna Bittencourt et al. Saúde mental do estudante de medicina: psicopatologia, estresse, sono e qualidade de vida. Revista Psicologia, Diversidade e Saúde, Salvador, v. 7 , n. 2, p. 245-254, mai. 2018. DOI: http://dx.doi.org/10.17267/23173394rpds.v7i2.1911. Disponível em: https://www5.bahiana.edu.br/index.ph p/psicologia/article/view/1911/0. Acesso em: 28 out 2019.

ARAÚJO, Mayle Gomes Ferreira. A saúde mental do estudante de medicina: uma análise durante a graduação.

Revista Científica Multidisciplinar Núcleo do Conhecimento. Ano 03, v. 05, n. 11, p. 97-106, 23 nov. 2018. DOI:

10.32749/nucleodoconhecimento.com. br/saude/estudante-de-medicina. ISSN:2448-095. Disponível em: https://www.nucleodoconhecimento.co m.br/saude/estudante-de-medicina Acesso em: 15 mar. 2019.

ARAUJO, Tainara Souza; BENTO, Fernanda Cristina de Jesus Colares; CUSTÓDIO, Misael Rabelo de Martins. Risco para o desenvolvimento de anorexia nervosa em estudantes universitárias de nutrição. Revisa, Valparaíso de Goiás, v. 7, n. 3, p. 192-1999, 2018. Disponível em:

http://revistafacesa.senaaires.com.br/in dex.php/revisa/article/view/320. Acesso em: 16 out. 2019.

ARENAS, Luccas Daniel et al. Pega Leve - saúde mental do estudante universitário: um relato de experiência. Trab. En(Cena), Palmas, v. 4, n. 2, p. 519-530, 2019. DOI:

10.20873/25261487V4N2P519. Disponível em:

https://lume.ufrgs.br/handle/10183/205 819. Acesso em: 13 jan. 2020.

BARDIN, Laurence. Análise de conteúdo. Lisboa: Edições 70, 2009.

BELASCO, Isabel Cristina; PASSINHO, Renata Soares; VIEIRA, Valéria Aparecida. Práticas integrativas e complementares na saúde mental do estudante universitário. Arquivos Brasileiros de Psicologia, Rio de Janeiro, v. 71, n. 1, p. 103-111, 2019. DOI: http://dx.doi.org/10.36482/18095267.ARBP2019v71i1p.103-111.

Disponível em: http://pepsic.bvsalud.org/scielo.php?sc ript=sci_arttext\&pid=S1809-

$52672019000100008 \& \operatorname{lng}=$ pt\&tlng $=$ pt . Acesso em: 25 mar. 2020. 
BORGES, Vanessa Lima; LOPES, Ederaldo José; LOPES, Renata Ferrarez Fernandes. Relações entre bullying e esquemas iniciais desadaptativos em estudantes universitários. Revista Brasileira de terapias cognitivas, Rio de Janeiro, v. 14, n. 1, p. 57-64, jan./jun. 2018. Disponível em: http://pepsic.bvsalud.org/pdf/rbtc/v14n 1/v14n1a08.pdf. Acesso em: 13 jan. 2020 .

BRASIL. Ministério da Saúde. Secretaria de Atenção à Saúde. Política nacional de práticas integrativas e complementares no SUS: atitude de ampliação de acesso. 2. ed. Brasília: Ministério da Saúde, 2015. 96 p.: il. Disponível em:

http://bvsms.saude.gov.br/bvs/publicac oes/politica_nacional_praticas_integrat ivas_complementares_2ed.pdf. Acesso em: 14 nov. 2019.

CARLETO, Cíntia Tavares et al. Adaptação à universidade e transtornos mentais comuns em graduandos de enfermagem. Revista Eletrônica de Enfermagem, Goiânia, v. 20, p. 1-11, 17 abr. 2018. DOI: 10.5216/ree. v. 20.43888. Disponível em: https://revistas.ufg.br/fen/article/view/ 43888/25414. Acesso em: 26 out. 2019.

COSTA, Camila Furlan; GOULART, Sueli. Capitalismo acadêmico e reformas neoliberais no ensino superior brasileiro. Cadernos EBAPE.BR, Rio de Janeiro, v. 16, n. 3, p. 396-409, jul./set. 2018 . DOI: https://doi.org/10.1590/1679-

395165788. Disponível em: https://www.scielo.br/pdf/cebape/v16n 3/1679-3951-cebape-16-03-396.pdf.

Acesso em: 13 mar. 2020.

FERNANDES, Márcia Astrês et al. Prevalência de sintomas ansiosos e depressivos em universitários de uma instituição pública. Rev. Bras. Enferm., Brasília, v. 71, supl. 5, p. 2298304, 2018. DOI:

https://doi.org/10.1590/0034-71672017-0752. Disponível em: https://www.scielo.br/pdf/reben/v71s5/ pt_0034-7167-reben-71-s5-2169.pdf.
Acesso em: 13 mar. 2020.

FONAPRACE/ANDIFES. Fórum Nacional de Pró-Reitores de Assuntos Estudantis. IV Pesquisa Nacional de Perfil Socioeconômico e Cultural dos Graduandos da IFES - 2014. Uberlândia: FONAPRACE, julho de 2016. Disponível

http://www.andifes.org.br/wp-

content/uploads/2017/11/Pesquisa-de-

Perfil-dos-Graduanso-das-

IFES_2014.pdf. Acesso em 15 set. 2017.

\section{FONAPRACE/ANDIFES. V Pesquisa} Nacional de Perfil Socioeconômico e Cultural dos (as) Graduandos (as) das IFES - 2018. Brasília: FONAPRACE/ANDIFES, 2018. Disponível em: http://www.andifes.org.br/vpesquisa-nacional-de-perfilsocioeconomico-e-cultural-dos-asgraduandos-as-das-ifes-2018/. Acesso em: 15 mai. 2020.

FREITAS, Ana Carolina Macedo de et al. Fatores intervenientes na qualidade de vida do estudante de enfermagem.

Rev enferm UFPE online, Recife, v. 12 , n. 9. p. 2376-2385, set. 2018. DOI: https://doi.org/10.5205/1981-8963v12i9a230110p2376-2385-2018. Disponível em:

https://periodicos.ufpe.br/revistas/revis taenfermagem/article/view/230110. Acesso em: 15 dez. 2019.

GAINO, Loraine Vivian et al. O conceito de saúde mental para profissionais de saúde. SMAD Revista Eletrônica Saúde Mental Álcool e Drogas (Edição em português), v. 14, n. 2, p. 108-116, abr./jun. 2018. DOI: 10.11606/issn.1806-

6976.smad.2018.149449. Disponível em:

http://pepsic.bvsalud.org/pdf/smad/v14 n2/07.pdf. Acesso em: 15 dez. 2019.

GALDERISI, Silvana et al. Toward a new definition of mental health. World Psychiatry, [S.L.], v. 14, n. 2, p. 231-233, jun. 2015. DOI: https://doi.org/10.1002/wps.20231. Disponível em:

https://onlinelibrary.wiley.com/doi/full /10.1002/wps.20231. Acesso em: 13 dez. 2019.

GIL, Isabella et al. Análise transversal de sintomas depressivos em estudantes de medicina: prevalência no primeiro ano de graduação. Revista PsicoFAE: Pluralidades em Saúde Mental, [S.1.], v. 7, n. 2, p. 99-118, fev. 2019. ISSN 2447-1798. Disponível em: https://revistapsicofae.fae.edu/psico/art icle/view/188\#: :text=Os\%20dados $\% 2$ Odemonstram\%20que\%20os, aumentar $\% 20$ a\%20consist $\%$ C3\%AAncia\%20do s\%20resultados. Acesso em: 15 jul. 2019

INEP. Instituto Nacional de Estudos e Pesquisas Educacionais Anísio Teixeira. Resumo técnico do Censo da Educação Superior 2017 [recurso eletrônico]. - Brasília: Instituto Nacional de Estudos e Pesquisas Educacionais Anísio Teixeira, 2019. Disponível em:

http://portal.inep.gov.br/informacaoda-publicacao/-

/asset_publisher/6JYIsGMAMkW1/do cument/id/6725796. Acesso em: 05 fev. 2020 .

HIRSCH, Carolina Domingues et al. Fatores percebidos pelos acadêmicos de enfermagem como desencadeadores do estresse no ambiente formativo. Texto contexto - enferm., Florianópolis, v. 27, n. 1, e0370014, 2018. DOI: https://doi.org/10.1590/0104-

07072018000370014. Disponível em https://www.scielo.br/pdf/tce/v27n1/01 04-0707-tce-27-01-e0370014.pdf.

Acesso em: 28 jan. 2019.

JONES, Kelvyn. A prática de métodos quantitativos. In: SOMEKH, Bridget; LEWIN, Cathy (org.). Teoria e métodos de pesquisa social. Petrópolis, RJ: Vozes, 2015. p. 265-277.

LEÃO, Andrea Mendes et al. Prevalência e fatores associados à depressão e ansiedade entre estudantes universitários da área da saúde de um grande centro urbano do nordeste do Brasil.

Rev. bras. educ. med., Brasília, v. 42, n. 4 , p. 55-65, dez. 2018. DOI: https://doi.org/10.1590/198152712015v42n4rb20180092. Disponí- 
vel em:

https://www.scielo.br/pdf/rbem/v42n4/ 1981-5271-rbem-42-4-0055.pdf. Acesso em: 28 out. 2019.

MACHADO, Sheila Francisca; VEIGA, Heila Magali da Silva; ALVES, Sérgio Henrique de Souza. Níveis de estresse em alunos de $3^{\mathrm{a}}$ série do ensino médio. Universitas: Ciências da Saúde, v. 9, n. 2, p. 35-52, 2011. DOI: 10.5102/UCS.V9I2.1362. Disponível em:

https://www.publicacoes.uniceub.br/ci enciasaude/article/view/1362. Acesso em: 24 jun. 2018.

MURAKAMI, Karolina et al. Atuações de um centro educacional e psicológico junto a estudantes universitários. Revista Brasileira de Orientação Profissional, v. 19, n. 1, p. 109119, jan./jun. 2018. DOI: http://dx.doi.org/1026707/1984-

7270/2019v19n1p109. Disponível em: http://pepsic.bvsalud.org/pdf/rbop/v19 n1/12.pdf. Acesso em: 25 nov. 2019.

NEVES, André Luiz Machado das et al. Saúde mental e universidade: experiência do "espaço de Atendimento PsicoSsocial (Epsico)', Trab.

En(Cena), Palmas, v. 4, n. 2, p. 531542, 2019. DOI:

10.20873/25261487V4N2P531. Dis-

ponível em:

https://sistemas.uft.edu.br/periodicos/i ndex.php/encena/article/view/7482/16 191. Acesso em: 20 jan.2010.

ORGANIZAÇÃO MUNDIAL DA SAÚDE - OMS. Estrategia de la OMS sobre medicina tradicional 2002-2005. Genebra, 2002. Disponível em:

https://www.paho.org/bra/index.php?o ption=com_docman \&view=download \&alias=796-estrategia-oms-sobremedicina-tradicional-2002-2005-

6\&category_slug=vigilancia-sanitaria959\&Itemid=965. Acesso em: 20 jul. 2017.

OLIVEIRA, Luís Adriano Freitas; BRILHANTE, Aline Veras Morais; LOURINHO, Lídia Andrade. Relação entre ocorrência de endometriose e sofrimento psíquico. Revista Brasileira em Promoção da Saúde, Fortaleza, v. 31, n. 4, p. 01-06, 2018. Disponível em:

https://periodicos.unifor.br/RBPS/artic le/view/8755. Acesso em: $19 \mathrm{dez}$. 2019.

ORGANIZACIÓN PANAMERICANA DE LA SALUD - PAHO Versión oficial en español de la obra original en Inglés: Depression and other common mental disorders: Global Health Estimates. WHO/MSD/MER, $2017 . \quad$ Disponível em: https://iris.paho.org/bitstream/handle/1 0665.2/34006/PAHONMH17005spa.pdf?sequence $=1 \&$ isAllowed $=\mathrm{y}$ Acesso em: 03 mai. 2020.

PEREIRA, Alexandre de Araújo; VIANNA, Paula Cambraia de Mendonça. Saúde Mental. Belo Horizonte: Nescon/UFMG, Coopmed, 2009. 76 p.: il. Disponível em:

https://www.nescon.medicina.ufmg.br/ biblioteca/imagem/1730.pdf. Acesso em: 17 dez. 2019.

PEREIRA, Rosane Elstner; MICELI, Bruno Carnevale. Fatores que influenciam o consumo de antidepressivos em universitários dos cursos de saúde de uma instituição de ensino superior privada do município de Sete Lagoas MG. Revista Brasileira de Ciências da Vida, v. 6, n. 5, p. 113-128. 2018. Disponível em:

http://jornal.faculdadecienciasdavida.c om.br/index.php/RBCV/article/view/8 82/457. Acesso em: 20 set. 2019.

PERRUSI, Artur. Sofrimento psíquico, individualismo e uso de psicotrópicos: saúde mental e individualidade contemporânea. Tempo soc., São Paulo, v. 27, n. 1, p. 139-159. DOI: http://dx.doi.org/10.1590/010320702015017. Disponível em: http://www.scielo.br/scielo.php?pid=S 0103-

20702015000100139\&script=sci_abstr act\&tlng=pt. Acesso em: 11 dez. 2019.

RAMOS, Fabiana Pinheiro et al. Intervenções psicológicas com universitários em serviços de apoio ao estudan- te. Revista Brasileira de Orientação Profissional, Florianópolis, v. 19, n. 2, p. 221-232, dez. 2018. DOI: http://dx.doi.org/1026707/1984-

7270/2019v19n2p221. Disponível em: http://pepsic.bvsalud.org/pdf/rbop/v19 n2/10.pdf. Acesso em: 28 out. 2019.

RIBEIRO, Rafaella do Carmo et al. Relação da qualidade de vida com problemas de saúde mental em universitários de medicina. Revista Brasileira de Qualidade de Vida, Universidade Tecnológica Federal do Paraná (UTFPR), Ponta Grossa, v. 10, n. 1, e7646, p.1-13, jan./mar. 2018. ISSN: 2175-0858. Disponível em:

https://periodicos.utfpr.edu.br/rbqv/arti cle/view/7646 Acesso em: 28 out. 2019.

RICHARDSON, Roberto Jarry et al. Pesquisa social: métodos e técnicas. São Paulo: Atlas, 2011.

RONDINA, Regina de Cassia et al. Queixas psicológicas e consumo de drogas em universitários atendidos em núcleo de assistência. SMAD, Rev. Eletrônica Saúde Mental Álcool Drog. (Ed. port.), Ribeirão Preto, v. 14, n. 2, p. 99-107, 2018. DOI:

10.11606/issn.1806-

6976.smad.2018.000420. Disponível em:

http://pepsic.bvsalud.org/pdf/smad/v14 n2/06.pdf. Acesso em: 19 out. 2019.

SANTANA, Vitor Santos; GONDIM, Sônia Maria Guedes. Regulação emocional, bem-estar psicológico e bemestar subjetivo. Estudos de Psicologia, Natal, v. 21, n. 1, p. 58-68, 2016. DOI: https://doi.org/10.5935/1678-

4669.20160007. Disponível em: https://www.scielo.br/pdf/epsic/v21n1/ 1413-294X-epsic-21-01-0058.pdf. Acesso em: 19 out. 2019.

SANTOS, Thiago Santana dos; ALMEIDA, Rafael Lima; ANACLETO, Geovana Mellisa Castrezana. Nível de estresse e qualidade de vida em universitários praticantes e não praticantes de esporte. Revista Científica UMC, Mogi das Cruzes, v. 3, n. 3, p. 1-3. 2018. ISSN 2525-5250. Disponível 
em:

http://seer.umc.br/index.php/revistaum c/article/view/474/366 Acesso em: 11 dez. 2019.

SILVA, Maria Vanessa Morais da; AZEVEDO, Ana Karina Silva. Um olhar sobre o suicídio: vivências e experiências de estudantes universitários. Revista Psicologia, Diversidade e Saúde, Salvador, v. 7, n. 3, p. 390401, 2018. DOI: $10.17267 / 2317-$ 3394rpds.v7i3.1908. Disponível em: https://www5.bahiana.edu.br/index.ph p/psicologia/article/view/1908/2125. Aceso em: $21 \mathrm{dez} .2019$.

SILVA, Ricardo Marinho; DALTRO, Mônica Ramos. Experiências de sofrimento e enfrentamento no ingressar ao ensino superior: narrativa autobiográfica. Revista Psicologia, Diversidade e Saúde, Salvador, v. 7, n. 3, p. 433-441, 2018. DOI:

http://dx.doi.org/10.17267/23173394rpds.v7i3.1930. Disponível em: https://www5.bahiana.edu.br/index.ph p/psicologia/article/view/1930 Acesso em: 11 dez. 2019.

SILVA, Andreia Keyth Batista de et al. Distúrbios de imagem e estado nutricional em universitários. COORTE - Revista Científica do Hospital Santa Rosa, [S.1], v. 2, p. 87-97, 2017. ISSN: 2594-6757. Disponível em: http://www.periodicos.univag.com.br/i ndex.php/mostranutri/article/view/669. Acesso em: 11 dez. 2019.

TAMASHIRO, Elisa Maria et al. Desafios e sucessos de um serviço de saúde mental para estudantes da saúde: a experiência do GRAPEME UNI-

CAMP. Rev Med., São Paulo, v. 98, n. 2, p. 148-51, mar./abr. 2019. DOI: http://dx.doi.org/10.11606/issn.16799836.v98i2p148-151. Disponível em: http://www.revistas.usp.br/revistadc/ar ticle/view/155448/153087. Acesso em: 12 fev. 2020.

TOTI, Thamires Gomes; BASTOS, Felipe Antônio; RODRIGUES, Phillipe. Fatores associados à ansiedade e depressão em estudantes universitários do curso de educação física. Revista
Saúde Física \& Mental, Belford Roxo (RJ), v. 6, n. 2, 2018. ISSN 2317-1790. Disponível em:

https://revista.uniabeu.edu.br/index.ph $\mathrm{p} / \mathrm{SFM} /$ article/view/3488. Acesso em: $12 \mathrm{dez} .2020$. 